\title{
Pelatihan Kader Kesehatan sebagai Upaya Sosialisasi RW Sehat
}

\author{
Udin Rosidin, Theresia Eriyani, Umar Sumarna \\ Fakultas. Keperawatan Universitas Padjadjaran \\ Email dinr8629@gmail.com,
}

\begin{abstract}
Abstrak
Pelaksanaan PHBS sebagai awal terbentuknya RW sehat adalah semua perilaku yang dilakukan atas kesadaran sendiri sehingga dapat menolong dirinya sendiri di bidang kesehatan dan berperan aktif dalam kegiatan-kegiatan kesehatan. Cakupan rumah tangga berperilaku hidup bersih dan sehat di Jawa Barat berdasarkan data yang diperoleh dari profil data kesehatan Indonesia tahun 2014 yang dikeluarkan oleh Kementerian Kesehatan sebesar 51,40 \%, dari 3.178.032 rumah tangga yang dipantau (Kemenkes RI, 2014). Posisi Jawa Barat berada pada nomor 12 dari 33 provinsi di Indonesia. Apabila kita amati angka tersebut ternyata angka jumlah rumah tangga di Jawa Barat yang melaksanakan PHBS jumlahnya dibawah angka nasional (56,58 \%). Belum dilaksanakannya PHBS pada masyarakat Garut salah satunya ditentukan oleh rendahnya pengetahuan masyarakat tentang PHBS. Upaya peningkatan pengetahuan tersebut perlu dilakukan melalui berbagai cara salah satunya pelatihan kader kesehatan. Tujuan kegiatan ini adalah untuk peningkatan pengetahuan kader kesehatan dalam memahami PHBS Rumah Tangga sebagai awal terbentuknya RW sehat. Metoda pelaksanaan Program Pengabdian Masyarakat ini adalah pelatihan kader kesehatan tentang PHBS melalui sosialisasi RW sehat dengan jumlah kader yang hadir sebanyak 25 orang. Kegiatan dimulai dari tahapan perencanaan, pelaksanaan, evaluasi, hingga penyusunan laporan. Hasil kegiatan berdasarkan uji analisis wilcoxon ada perubahan signifikan dalam pengetahuan (Z--4.298) dengan rata pre test 46,2 (SD.8,57)) dan post test 67.3 (SD 9,59). Kesimpulan. Pelaksanaan kegiatan mendapat apresiasi dari seluruh kader kesehatan dan aparat pemerintah yang hadir.
\end{abstract}

Kata kunci : Pelatihan, kader kesehatan, PHBS, RW Sehat.

\begin{abstract}
Abstrac
Implementation of PHBS as the beginning of the formation of a healthy $R W$ is behavior carried out on its own awareness, so it can help they self in the health sector and play an active role in health activities. The coverage of clean and healthy living households in West Java based on data obtained from the profile of Indonesia's health data in 2014 issued by the Ministry of Health was 51.40\%, out of 3,178,032 households monitored (RI Ministry of Health, 2014). The position of West Java is in number 12 out of 33 provinces in Indonesia. If we observe this number, it turns out that the number of households in West Java implementing PHBS is below the national figure (56.58\%). One of the reasons for the implementation of PHBS in Garut community is determined by the low level of public knowledge about PHBS. Efforts to increase this knowledge need to be done through various methods, one of which is health kader training. The purpose of this activity is to increase the knowledge of health kader in understanding household PHBS as the beginning of the formation of a healthy RW. The method of implementing this Community Service Program is training health kader about PHBS. Through this program health kader are trained on how to implement PHBS for each household. The number of kader present were 25 people. Activities begin from the stages of planning, implementation, evaluation, and preparation of reports. The results of the activity based on the Wilcoxon analysis test there were significant changes in knowledge $(Z-4,298)$ with a mean pre test of 46.2 (SD.8,57) and post test67.3 (SD 9.59). Conclusion. The activity received appreciation from all health cadres and government officials present. It is hoped that this activity can be an effort to further improve PHBS knowledge and actions as the initial formation of a Healthy $R W$
\end{abstract}

Keywords: Training, Kader Health, PHBS, Healthy RW. 


\section{Pendahuluan}

Kemampuan hidup sehat merupakan hak asasi manusia dan merupakan intervensi untuk kehidupan yang produktif. Sehat juga merupakan prasyarat agar hidup kita menjadi berarti, sejahtera, dan bahagia. Hal ini di dukung oleh kebijakan pemerintah pusat dalam hal ini Kementerian Kesehatan dengan program PHBS (Perilaku Hidup Bersih dan Sehat) serta program Germas (Gerakan masyarakat Sehat) dan Kementerian Dalam Negeri dengan program Kecamatan Sehat. Untuk mewujudkan hal tersebut setiap warga negara wajib menjaga, memelihara, melaksanakan dan meningkatkan hidup sehat dengan merubah cara pandang menjadi paradigma sehat. Hidup sehat merupakan upaya untuk mengatasi perubahan pola penyakit dari penyakit infeksi ke penyakit degeneratif (Sarvasti, 2012)

Dalam rangka mengoperasionalkan paradigma sehat khususnya yang berkaitan dengan promosi kesehatan di Indonesia, Diperlukan upaya upaya peningkatan pemahaman semua unsur di masyarakat tentang Perilaku Hidup Bersih dan Sehat sesuai dengan apa yang tertuang dalam Peraturan Menteri Kesehatan Republik Indonesia Nomor : 2269/MENKES/PER/XI/2011. Peraturan tersebut mengatur upaya peningkatan perilaku hidup bersih dan sehat atau disingkat PHBS di seluruh Indonesia dengan mengacu kepada pola manajemen PHBS, mulai dari tahap pengkajian, perencanaan, dan pelaksanaan serta pemantauan dan penilaian. Upaya tersebut dilakukan untuk memberdayakan masyarakat dalam memelihara, meningkatkan dan melindungi kesehatannya sehingga masyarakat sadar, mau, dan mampu secara mandiri ikut aktif dalam meningkatkan status kesehatannya. Kita menyadari bahwa upaya tersebut bukanlah suatu hal yang mudah karena upaya tersebut berkaitan sangat erat dengan masalah perilaku sedangkan masalah perilaku merupakan masalah yang khas dan kompleks. PHBS dapat diterapkan dalam kehidupan sehari-hari pada lingkungan sekitar, seperti lingkungan rumah tangga, sekolah, dan tempat kerja. PHBS pada tatanan rumah tangga merupakan bentuk perwujudan paradigma sehat dalam budaya hidup perorangan dan keluarga, yang bertujuan untuk meningkatkan, memelihara dan melindungi kesehatannya.

Cakupan rumah tangga berperilaku hidup bersih dan sehat di Jawa Barat berdasarkan data yang diperoleh dari profil data kesehatan Indonesia tahun 2014 yang dikeluarkan oleh kementerian kesehatan sebesar 51,40 \%, dari 3.178.032 rumah tangga yang dipantau (Kemenkes RI, 2014). Posisi Jawa Barat berada pada nomor 12 dari 33 provinsi di Indonesia. Apabila kita amati angka tersebut ternyata angka jumlah rumah tangga di Jawa Barat yang melaksanakan PHBS jumlahnya dibawah angka nasional (56,58 \%). Berdasarkan data yang dikeluarkan oleh Dinas Kesehatan Provinsi Jawa Barat tahun 2014 jumlah rumah 
tangga yang berperilaku hidup bersih dan sehat di Kabupaten Garut tahun 2011 sebesar $58,20 \%$, tahun 2012 sebesar 33,80\%, tahun 2013 sebesar $35 \%$ dan tahun 2014 sebesar $51,70 \%$ (Dinkes Kab Garut, 2015). Dari data tersebut dapat ditarik kesimpulan bahwa masih banyak masyarakat Kabupaten Garut belum melaksanakan perilaku hidup bersih dan sehat.

Belum dilaksanakannya PHBS pada masyarakat Garut salah satunya ditentukan oleh rendahnya pengetahuan masyarakat tentang PHBS. Hal ini akan menghambat pencapaian Kabupaten Garut menjadi Garut Sehat. Kabupaten Garut harus diawali dengan Kecamatan Sehat, Desa Sehat, RW sehat dan Keluarga Sehat. Dalam survey awal yang dilakukan di RW 12 Desa Jayaraga Kecamatan Tarogong Kidul Kabupaten Garut didapatkan data bahwa pengetahuan masyarakat tentang PHBS Rumah Tangga kurang dari setengahnya (43,4 \%) mempunyai pengetahuan kurang baik dan lebih dari setengahnya (56,6 \%) masyarakat mempunyai pengetahuannya baik. Upaya peningkatan pengetahuan tersebut perlu dilakukan melalui berbagai cara salah satunya meningkatkan pengetahuan kader kesehatan melalui pelatihan. Hasil wawancara dengan pengurus kader kesehatan di Desa Jayaraga, mengatakan bahwa kader kesehatan Desa Jayaraga belum terpapar informasi secara terstruktur baik dalam bentuk pelatihan atau penyuluhan tentang RW Sehat. Pelaksanaan RW sehat merupakan output dari pelaksanaan perilaku hidup bersih dan sehat.

Kader kesehatan merupakan tokoh masyarakat yang akan menjadi panutan dalam pelaksanaan hidup sehat. Kader kesehatan merupakan sasaran yang tepat dalam pelaksanaan program tersebut karena dianggap sebagai tempat rujukan pertama pelayanan kesehatan. Kader ini adalah kepanjangan tangan dari puskesmas ( Trisnawati, 2008) Agar masyarakat dapat melaksanakan PHBS maka langkah strategis untuk membentuk RW sehat harus diawali dengan tokohnya. Berdasarkan permasalahan tersebut maka kami tertarik untuk melakukan kegiatan PPM dengan judul Pelatihan Kader kesehatan sebagai upaya sosialisasi RW sehat di Desa Jayaraga Kecamatan Tarogong Kidul Kabupaten Garut.

\section{Metode}

Metode pelaksanaan Program Pengabdian Masyarakat ini adalah pelatihan kader kesehatan melalui upaya sosialisasi RW Sehat. Pelatihan pada kader kesehatan merupakan salah satu upaya inspirasi kegiatan PPM (Program Pengabdian Masyarakat). Jumlah peserta kader kesehatan yang hadir dalam pelaksanaan kegiatan tersebut adalah sebanyak 25 orang. Kegiatan dimulai dari tahapan perencanaan/persiapan yang diawali dengan berkoordinasi dengan pengurus kader kesehatan dan aparat pemerintah Desa Jayaraga untuk menyepakati 
kembali tujuan, waktu dan tempat dan peserta dari pelaksanaan kegiatan. Pelaksanaan kegiatan terdiri dari beberapa sesi, pertama yaitu penyajian hasil identifikasi pelaksanaan PHBS sebagai indikator RW Sehat di Desa Jayaraga kemudian dilanjut sesi diskusi tentang hambatan dan strategi pelaksanaan RW Sehat dan ketiga yaitu peningkatan pemahaman dan pengetahuan tentang PHBS sebagai indikator RW Sehat yang diawali dengan pre test dan pemberian materi terkait PHBS dan diakhiri dengan post test sebagai evaluasi kegiatan pemberian materi. Kegiatan dipandu oleh narasumber sebagai fasilitator dengan dibantu peralatan dan perlengkapan pendukung pelatihan seperti leaflet dan media visual/LCD. Untuk mengevaluasi signifikansi kegiatan pelatihan terhadap pengetahuan dan sikap kader kesehatan dilakukan uji distribusi dan analisis inferensial dengan uji wilcoxon.

\section{Hasil}

Kegiatan pengabdian ini mendapat apresiasi positif baik dari aparat pemerintahan Desa Jayaraga maupun dari pihak puskesmas yang saat pelaksanaan kegiatan pelatihan ikut hadir. Peserta sangat antusias mengikuti kegiatan pelatihan dari awal sampai akhir kegiatan. Pelaksanaan kegiatan dibagi menjadi 3 tahap yaitu pertama penyajian hasil indentifikasi pelaksanaan PHBS sebagai indikator RW Sehat, diskusi terkasil hasil identifikasi dan pemberian materi. Tahap pertama yaitu mendengarkan laporan hasil survey yang dilakukan oleh mahasiswa tentang pelaksanaan PHBS rumah tangga di Desa Jayaraga. Tahap kedua melakukan diskusi dengan kader kesehatan tentang hambatan dan strategi pelaksanaan PHBS di Desa Jayaraga dan tahap terakhir adalah pemberian materi tentang indikator PHBS. Jumlah kader yang hadir dalam kegiatan tersebut adalah sebanyak 25 orang. Adapun karakteristik peserta yang mengikuti kegiatan tersebut adalah sebagai berikut:

Tabel 1 Karakateristik Kader Kesehatan (N=25)

\begin{tabular}{llcc}
\hline No. & Variabel & N & $\begin{array}{c}\text { Persentase } \\
(\%)\end{array}$ \\
\hline 1. & Usia: & & \\
& $30-40$ tahun & 5 & 20 \\
& $41-50$ tahun & 12 & 48 \\
& $51-60$ & 8 & 32 \\
\hline 2. & Suku : & & \\
& Sunda & 25 & 100 \\
& Jawa & 0 & 0 \\
\hline 3. & Pekerjaan : & & \\
& Tidak bekerja & 20 & 80 \\
& Buruh & 0 & 0 \\
& Pensiun PNS & 2 & 8 \\
& Wiraswasta & 3 & 12 \\
\hline
\end{tabular}


Udin Rosidin : Pelatihan Kader Kesehatan sebagai Upaya Sosialisasi RW Sehat

\begin{tabular}{llcc}
\hline No. & Variabel & N & $\begin{array}{c}\text { Persentase } \\
(\boldsymbol{\%})\end{array}$ \\
\hline 4. & Pendidikan: & & \\
& SD & 2 & 8 \\
& SLTP & 1 & 4 \\
& SLTA & 18 & 72 \\
& PT & 4 & 16 \\
\hline 5. & Lama & & \\
& menjadi & & \\
& kader & 15 & 60 \\
& 1-5 tahun & 3 & 12 \\
& 6-10 tahun & 7 & 28 \\
\hline
\end{tabular}

Dari tabel 1, usia kader kesehatan yang mengikuti pelatihan sebagian besar lebih berusia 41-50 tahun (48\%). Hampir seluruh kader kesehatan tidak bekerja atau ibu rumah tangga (80 \%). Tingkat pendidikan kader kesehatan sebagian besar adalah SLTA (72 \%). Sedangkan pengalaman menjadi kader lebih dari setengahnya menjadi kader selama $1-5$ tahun $(60 \%)$.

Uji distribusi pengetahuan kader dilakukan sebelum dan sesudah pelatihan Hasil untuk pengetahuan sebelum adalah $\mathrm{p}=0.11$, sedangkan untuk pengetahuan sesudah adalah $\mathrm{p}$ $=0.00$, Selanjutnya Wilcoxon digunakan untuk analisis uji inferensial.

Tabel 2 Hasil Uji Perbedaan Rata-Rata Pengetahuan Kader Sebelum dan Sesudah Pelatihan $\operatorname{Kader}(\mathrm{N}=25)$

\begin{tabular}{ccccc}
\hline Variabel & $\begin{array}{c}\text { Sebelum } \\
\text { M(SD) }\end{array}$ & $\begin{array}{c}\text { Sesudah } \\
\text { M (SD) }\end{array}$ & $\mathbf{Z}$ & $\boldsymbol{p}$ \\
\hline Pengetahuan & $46.2(8.57)$ & $67.3(9.59)$ & -4.298 & 0.00
\end{tabular}

$\mathrm{M}(\mathrm{SD})=$ Mean $($ Standar Deviasi)

Berdasarkan tabel 2, dapat dilihat bahwa rata rata nilai pengetahuan sebelum dilaksanakan pelatihan adalah 46,2 dengan standar deviasi 8,57 dan rata rata nilai meningkat menjadi 67,3 dengan standart deviasi 9,59 setelah dilaksanakan pelatihan. Data tersebut menunjukkan ada perbedaan yang signifikan pengetahuan kader kesehatan sebelum dan sesudah pelatihan kader. 
Udin Rosidin : Pelatihan Kader Kesehatan sebagai Upaya Sosialisasi RW Sehat

\section{Pembahasan}

Rangkaian kegiatan pelatihan kader kesehatan di Desa Jayaraga dapat meningkatkan pengetahuan kader kesehatan tentang PHBS Rumah Tangga. Hasil ini sejalan dengan Kosasih (2018) bahwa terjadi peningkatan tingkat pengetahuan kader kesehatan sebelum dilakukan pelatihan dan sesudah dilakukan pelatihan. Pelatihan yang dilakukan berhubungan dengan perilaku penyampaian informasi dengan demikian maka pelatihan ini juga mempengaruhi pengetahuan sesorang dalam menyampaikan informasi tertentu. Meningkatnya pengetahuan kader kesehatan tentang PHBS dapat menjadi modal awal untuk terbentunya RW Sehat. Di awal kegiatan, pada saat penyajian hasil identifikasi tentang pelaksanaan PHBS Rumah Tangga dan hasil pre test sebagian besar kader kesehatan belum mengetahui dan memahami secara jelas tentang pelaksanaan PHBS Rumah Tangga. Peserta yang hadir sangat antusias mengikuti kegiatan, karena pemaparan informasi tentang PHBS Rumah Tangga merupakan hal yang sangat mendasar untuk pembentukan RW sehat. Meskipun ada sebagian kader kesehatan di awal kegiatan saat tanya jawab ada beberapa kader kesehatan mampu memaparkan tentang PHBS namun secara keseluruhan kader belum memahami secara jelas tentang PHBS sebagai indikator RW sehat. Adanya informasi tentang PHBS Rumah Tangga yang kader kesehatan dapatkan dalam kegiatan ini menjadikan kader lebih memahami tentang PHBS Rumah Tangga dan sangat memahami terbentuknya RW Sehat. Informasi...

Peningkatan pengetahuan kader kesehatan tersebut sangat ditunjang oleh karakteristik kader kesehatan yang dimilikinya seperti umur, tingkat pendidikan, pekerjaan dan lamanya menjadi kader kesehatan. Hal ini sesuai dengan teori yang dikemukakan oleh Notoatmodjo (2010) bahwa karakteristik: sosial budaya, pengalaman dapat mempengaruhi pengetahuan, keinginan, sikap dan niat seseorang dalam melaksanakan sebuah perilaku. Perilaku Hidup Bersih dan Sehat (PHBS) sebagai indikator pembentukan RW Sehat adalah semua perilaku yang dilakukan atas kesadaran sendiri sehingga dapat menolong dirinya sendiri di bidang kesehatan dan berperan aktif dalam kegiatan-kegiatan kesehatan (Kemenkes, 2013). Untuk dapat melakukan perilaku tersebut sangatlah diperlukan adanya pengetahuan yang mendukung terhadap pelaksanaan PHBS. Menurut teori L. Green (1990) dalam Notoatmodjo (2010) perilaku pelaksanaan PHBS tersebut akan ditentukan oleh banyak faktor yaitu predisposing factor, enabling factor dan reinforcing factor. Pada Predisposing factors seperti faktor pengetahuan, sikap, kepercayaan dan keyakinan responden terhadap PBHS. Enabling factors adalah akses responden ke pelayanan kesehatan dan ketersediaan sarana. Sedangkan reinforcing factors adalah perilaku petugas kesehatan dan perilaku tokoh 
Udin Rosidin : Pelatihan Kader Kesehatan sebagai Upaya Sosialisasi RW Sehat

masyarakat. Peningkatan pengetahuan dan pemahaman kader kesehatan tentang PHBS Rumah Tangga membawa perubahan yang signifikan terhadap sikap kader kesehatan dalam memahami PHBS. Pengetahuan dan sikap kader kesehatan tersebut diharapkan dapat menjadi dasar upaya untuk pembentukan RW sehat di Desa Jayaraga.

\section{Simpulan}

Berdasarkan hasil kegiatan pelatihan kader kesehatan tentang PHBS Rumah Tangga sebagai indikator RW sehat, membawa dampak yang signifikan dalam mendasari pengetahuan dan pemahaman kader kesehatan mengenai PHBS Rumah Tangga. Kader kesehatan sebagai tokoh masyarakat dibidang kesehatan dan sebagai ujung tombak penggerak kesehatan di masyarakat dapat menjadi contoh dan panutan dalam upaya untuk meningkatkan Pelaksanaan PHBS Rumah Tangga di Desa Jayaraga. Perlu adanya optimalisasi peran kader kesehatan dalam beberapa kegiatan kesehatan yang berbasis masyarakat. Sehingga seluruh pelayanan kesehatan yang ada dimasyarakat dapat tersosialisasikan dengan baik. Rencana tindak lanjut dari kegiatan pengabdian ini adalah tindak lanjut kegiatan yang dilaksanakan oleh kader kesehatan kepada masyarakat. Dengan meningkatnya pengetahuan seluruh masyarakat tentang PHBS maka diharapkan terbentuknya RW sehat semakin lebih cepat.

\section{Ucapan Terimakasih}

Penulis menyampaikan terimakasih kepada semua pihak yang telah membantu dalam pelaksanaan kegiatan Program Pengabdian Masyarakat ini. Secara khusus penulis ingin mengucapkan terimakasih dan penghargaan yang setinggi-tingginya kepada: Prof. Dr. Med. Tri Hanggono Achmad, dr., selaku Rektor Universitas Padjadjaran dan $\mathrm{Hj}$. Henny Suzana Mediani.S.Kp.,MNg.,Ph.D, selaku Dekan fakultas Keperawatan Universitas Padjadjaran atas kesempatan dan dukungan yang telah diberikan kepada penulis untuk dapat melaksanakan kegiatan Program Pengabdian Masyarakat ini. Penulis juga menyampaikan terimakasih kepada Kepala desa Jayaraga Kabupaten Garut, Puskesmas Haurpanggung Kabupaten Garut, serta para kader kesehatan desa Jayaraga, atas kesempatan dan partisipasinya dalam pelaksanaan kegiatan Program Pengabdian Masyarakat ini. Semoga Alloh SWT membalasnya. 
Udin Rosidin : Pelatihan Kader Kesehatan sebagai Upaya Sosialisasi RW Sehat

\section{Daftar Pustaka}

Dinas Kesehatan Kabupaten Garut. 2015. Pembangunan Kesehatan Kabupaten Garut tahun 2010-2014.

Kementerian Kesehatan RI. 2012. Rencana Strategis Kementrian Kesehatan 2010-2014.

Kementerian Kesehatan 20, 14. Profil Kesehatan Indonesia 2013.

Kementerian Kesehatan, 2013. PHBS Di Rumah Tangga.

Kosasih, C. E., Isabella, C., \& Sriati, A. (2018). Upaya Peningkatan Gizi Balita Melalui Pelatihan Kader Kesehatan di Desa Cilumba dan Gunungsari Kabupaten Tasikmalaya. Media Karya Kesehatan, 1(1).

Notoatmodjo Soekidjo. Prof, Dr. 1983. Metodoligi Pendidikan dan Pengajaran, Jakarta. Badan Penerbit Kesehatan Masyarakat.

Notoatmodjo Soekidjo. Prof, Dr. 1983. Pengantar Pendidikan Kesehatan dan Ilmu Perilaku, Jogjakarta. Andi Offset.

Sarvasti, 2012. Penyakit Jantung Dan Pembuluh Darah Penyebab Utama Kematian Di Dunia, RSU Husada Utama Surabaya.

Trisnawati Azzizah Gama, 2008, Pelatihan Peningkatan Kemampuan Kader Kesehatan Dalam Penanganan Tuberkulosis (Tbc) Di Wilayah Kerja Puskesmas Gemolong Ii Sragen, WARTA, Vol .11, No. 2, September 2008: 150 - 158 